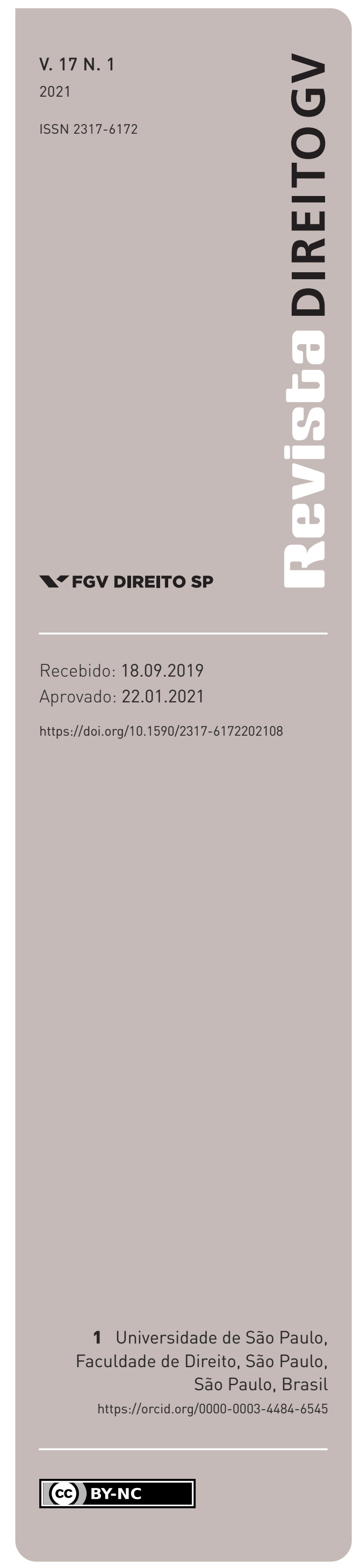

\section{MÉTODOS DE RESOLUÇÃO DIGITAL DE CONTROVÉRSIAS: ESTADO DA ARTE DE SUAS APLICAÇÕES E DESAFIOS}

ONLINE DISPUTE RESOLUTION METHODS: STATE-OF-THE-ART OF ITS APPLICATION AND CHALLENGES

Carolina Stange Azevedo Moulin ${ }^{1}$

\section{Resumo}

Métodos de resolução digital de conflitos, referidos na literatura como online dispute resolution (ODR), são uma categoria guarda-chuva que abriga a aplicação de tecnologia à prática jurídica em diferentes níveis de complexidade e automação. 0 objetivo deste artigo é fornecer um panorama da produção científica sobre o conceito e as modalidades de ODR, suas principais aplicações práticas e os desafios para sua regulação. 0 método empregado foi a revisão bibliográfica. Com base em extensiva análise da produção científica nacional e internacional, concluiu-se que as duas modalidades cardinais dos softwares ODR são os sistemas instrumentais e os principais, subdividindo-se os últimos em sistemas expert e de suporte. Tecnologias ODR proporcionam economias de escala e adicionam funcionalidades que elevam a qualidade do processo decisório. A utilidade dos mecanismos de ODR ultrapassa o âmbito das relações consumeristas virtuais, seu domínio original de aplicação, e se expande para disputas familiares, sucessórias, administrativas e de propriedade intelectual. Há um movimento de regulação transnacional dos mecanismos de ODR por entes privados, pela União Europeia e pelas Nações Unidas. A normatização dos métodos de resolução digital de controvérsias pelos Estados é fundamental para assegurar que pressupostos de acesso à justiça sejam satisfeitos em procedimentos on-line.

\section{Palavras-chave}

Resolução on-line de conflitos; sistemas de suporte à decisão; inteligência artificial; justiça multiportas; acesso à justiça.

\begin{abstract}
Online dispute resolution methods (ODR) are an umbrella category that encompasses the application of technology to legal practice at different levels of complexity and automation. This article aims to provide an overview of scientific literature on the concept and modalities of ODR, its main practical applications and the challenges for its regulation. The method employed was literature review. Drawing on extensive review of national and international literature on the topic, it concludes that the two central modalities of ODR software are principal and instrument systems, the latter being subdivided into expert and support systems. ODR technologies foster scale savings in conflict resolution and add functionalities that elevate the quality of decision-making. The utility of ODR mechanisms goes beyond the scope of virtual consumerist relationships, their original domain of application, and expands into family, inheritance, administrative and intellectual property disputes. There is a movement of transnational regulation of ODR mechanisms by private entities, the European Union and the United Nations. The standardization of online dispute resolution methods by states is critical to ensuring that access to justice; procedural justice and material justice are met in ODR.
\end{abstract}




\section{Keywords}

Online dispute resolution methods; decision support systems; artificial intelligence; multidoor justice; access to justice.

\section{INTRODUÇÃO' ${ }^{1}$}

A aplicação de tecnologia à prática jurídica não é novidade no Brasil - softwares de gestão de processos e pesquisa de jurisprudência têm sido implementados há mais de uma década pelo Poder Judiciário e pelo setor legal privado (CNJ, 2018a, p. 59). Todavia, o conceito de resolução digital de controvérsias (doravante denominado ODR, sigla para a expressão em inglês online dispute resolution) ainda é pouco conhecido por parte da comunidade acadêmica e dos praticantes do direito, apesar de o debate nacional e internacional sobre o tema já datar de mais de duas décadas.

As ferramentas de ODR surgiram nos anos 1990 com o boom do comércio eletrônico atrelado à popularização da internet e incorporaram princípios dos métodos adequados de resolução de conflitos (ADR, sigla para a expressão em inglês alternative dispute resolution) a relações contratuais virtuais massificadas. Com o tempo, percebeu-se a utilidade da ODR para outros tipos de litígio, como partilhas de bens em divórcios e inventários em conflitos sucessórios. A digitalização das ferramentas de resolução de controvérsias associa-se à passagem da sociedade industrial para a sociedade da informação e à naturalização do uso da tecnologia no dia a dia de número cada vez maior de pessoas.

Atualmente, os softwares abrigados sob a expressão guarda-chuva online dispute resolution executam funções que variam desde o simples fornecimento de ambiente virtual de comunicação entre as partes até a produção autônoma de decisão arbitral vinculante, e encontram aplicabilidade tanto no sistema privado quanto no sistema público de solução de controvérsias. O contínuo desenvolvimento de técnicas de ODR se baseia no potencial da tecnologia de tornar a resolução de conflitos não apenas mais rápida e mais barata, trazendo ganhos de eficiência, mas de introduzir novas configurações capazes de melhorar a qualidade do processo, incrementando a percepção de justiça procedimental pelas partes e ampliando o acesso à justiça.

1 Artigo premiado no I Concurso de Artigos Científicos do Superior Tribunal de Justiça - 30 anos do Tribunal da Cidadania, realizado em 2019, com modificações. 
Este artigo objetiva fornecer um panorama extensivo da produção científica nacional e internacional sobre o conceito e as modalidades de ODR, suas principais aplicações práticas e os desafios para sua regulação. A revisão bibliográfica foi realizada com amostragem bola de neve (snowball sampling), tipo de amostragem não probabilística que utiliza cadeias de referência para fins exploratórios, geralmente com três objetivos: compreender melhor um tema, testar a viabilidade de um estudo mais abrangente e desenvolver métodos a serem aplicados em um estudo subsequente (VINUTO, 2014, p. 205). A revisão bibliográfica em bola de neve se inicia com a localização de textos-chave, também chamados de sementes, que vingarão na ampliação das informações coletadas no estudo e em novas sementes, até o atingimento do ponto de saturação do quadro de amostragem, quando os documentos encontrados não trazem informações novas à análise (VINUTO, 2014, p. 203). Neste artigo, textos sementes iniciais, exploratórios sobre o conceito e as modalidades de ODR, conduziram ao aprofundamento sobre experiências e modo de funcionamento dos sistemas ODR principais de apoio à decisão, informações trazidas por textos sementes de segunda ordem na amostragem.

Na medida em que a dogmática jurídica pode ser compreendida como uma tecnologia que articula um discurso eminentemente persuasivo e envolve uma espécie de sincretismo de "categorias indiferenciadas, ao mesmo tempo normativas, sociológicas, naturalistas, positivistas, políticas, metafísicas" (FERRAZ JR., 2015, p. 176-177) com vistas a “comp[or], deline[ar] e circunscreve[r] procedimentos que conduzem a autoridade à tomada de decisão" (FERRAZ JR., 2015, p. 80), enxergam-se similitudes entre os produtos desta, caso da literatura ora revisada, e o processo de produção do conhecimento científico a partir da noção de crédito como recompensa descrito por Latour e Woolgar (1986). Dessa forma, tendo em vista que os mecanismos de citação na literatura dogmática se estruturam antropologicamente a partir de sistemas de credibilidade e prestígio entre pares (LATOUR e WOOLGAR, 1986, p. 197), a modelagem mais apropriada para acessar o estado da arte do campo das ferramentas de ODR passa a ser constituível via snowball sampling. A revisão por amostragem bola de neve reflete a produção científica da área na medida em que a seleção da bibliografia por cadeias de referência espelha adequadamente as dinâmicas sociais das pesquisas em dogmática jurídica.

Na primeira seção do artigo será esclarecido o que são os métodos de resolução digital de controvérsias e explicadas suas duas modalidades centrais: sistemas principais e sistemas instrumentais. Na segunda seção, a distinção entre sistemas periciais e sistemas de apoio à decisão será aprofundada, com recurso ao debate entre os paradigmas representacionista e fenomenológico que influenciou o redirecionamento de foco de sistemas periciais para sistemas de apoio à decisão. Na terceira seção do artigo, será detalhado o modo de funcionamento de dois sistemas de apoio à decisão correntemente utilizados, o Adjusted Winner, aplicado no direito de família australiano, e o UMCourt, implementado na Universidade do Minho, em Portugal. Serão relatadas, ainda, outras experiências de implementação de ODR por empresas e Estados, bem como retratado o incentivo à adoção de ODR por organizações 
supranacionais. Discutir-se-á, na quarta seção, a relação entre ODR e as concepções de acesso à justiça, justiça procedimental e justiça material. Na última seção, serão apresentadas as conclusões.

\section{CONCEITO E MODAlIDADES}

Métodos de resolução digital de controvérsias são espaços virtuais em que as partes dispõem de uma variedade de ferramentas para solucionar uma disputa (LODDER e ZELEZNIKOW, 2005 , p. 300), plataformas baseadas na internet que permitem às partes completarem o processo de tratamento de um conflito (SELA, 2018, p. 93).

$\mathrm{Na}$ época inicial de seu desenvolvimento, predominava a noção de que os métodos de resolução digital de disputas mantinham uma relação de dependência com as formas adequadas de resolução de litígios. Ainda há autores que conceituam a ODR como a abordagem da ADR que se apoia nos meios tecnológicos (CAFÉ et al., 2010, p. 2), a utilização da internet para realizar ADR (EBNER e ZELEZNIKOW, 2015, p. 144) ou a oferta de ADR por meios digitais (BRAEUTIGAM, 2006, p. 281).

À medida que a pesquisa em ODR avança, traça-se uma distinção clara entre os dois tipos de mecanismos. Sob a rubrica ADR se enquadram procedimentos de resolução de conflitos que fogem ao processo judicial litigioso, como negociação, arbitragem, mediação e conciliação (as duas últimas tanto na forma estatal quanto privada). A categoria ODR, a seu turno, engloba softwares que auxiliam o ser humano na tomada de decisão, seja ela resultado de um processo judicial ou extrajudicial, heterocompositivo ou autocompositivo. Concebe-se, hoje, que os métodos digitais são uma nova porta para solucionar conflitos que talvez não possam ser dirimidos nem mesmo por mecanismos de ADR (ARBIX, 2015, p. 221).

Os meios on-line de resolução de litígios classificam-se, conforme seu nível de autonomia, em sistemas instrumentais (ou de primeira geração) e sistemas principais (ou de segunda geração). ODR instrumentais são essencialmente plataformas virtuais especializadas que facilitam a comunicação e o compartilhamento de informação entre as partes ou por uma das partes (SELA, 2018, p. 100). Constituem a abordagem mais simples da integração tecnológica à prática jurídica. Nessa modalidade figuram ferramentas de pesquisa de jurisprudência, aplicativos de mensagens e videoconferência, sistemas de gestão eletrônica de processos, programas de edição compartilhada de documentos, softwares de elaboração automatizada de textos jurídicos (contratos, petições, etc.).

ODR principais vão além de permitir a comunicação e o acesso à informação pelas partes, exercendo um papel proativo na resolução da disputa. Esses sistemas empregam inteligência artificial para identificar normas e linhas de argumentação aplicáveis ao conflito, refinar interesses, objetivos e preferências das partes, sugerir soluções consensuais e apontar o resultado mais provável do litígio em um processo judicial (SELA, 2018, p. 100). Em razão de tais propriedades, diz-se que os softwares principais são capazes de tomar a decisão resolutória da controvérsia. 
A autonomia dos sistemas principais na tomada de decisão não é sinônimo de vinculação obrigatória ao resultado por eles proposto. As partes, nos métodos consensuais, e o terceiro neutro, nos litigiosos, devem ter total liberdade para aceitar, rejeitar ou alterar as recomendações feitas pelas tecnologias de ODR. Algoritmos processam maior quantidade de informação em menor tempo, mas prevalece o entendimento de que aos humanos deve pertencer a autoridade final pela tomada de decisão na administração da justiça e na pacificação de conflitos sociais. O paradigma proposto, portanto, não é o da substituição das partes e do terceiro neutro por robôs, mas o da tecnologia como a quarta parte (KATSH e RIFKIN, 2001, p. 93), inteligência artificial como instrumento de apoio à decisão (ANDRADE, CARNEIRO e NOVAIS, 2010, p. 11). A ferramenta de ODR não se iguala em influência ao terceiro neutro (árbitro, mediador ou juiz) na resolução do conflito, mas funciona como um aliado, colaborador e parceiro no processo (BRANNIGAN, 2007, p. 6916).

O emprego massivo da expressão "inteligência artificial" (IA) no debate público atual é frequentemente acompanhado de indefinição conceitual. Críticas bem-humoradas à IA a sugerem como "tudo o que computadores ainda não conseguem fazer" ou "tentar resolver por computador um problema que um humano consegue resolver mais rápido" (LODDER e ZELEZNIKOW, 2005, p. 288). A primeira definição foi cunhada por John McCarthy em 1956, quando ele descreveu IA como "ciência e engenharia de fazer máquinas inteligentes" (MCCARTHY, 2007, p. 1). Desde então, o conceito sofreu pouca alteração em seu uso corrente. IA continua sendo definida de forma abrangente como atividade dedicada à automatização da inteligência, compreendendo-se inteligência como a qualidade que permite a uma entidade funcionar adequadamente em seu ambiente (EZTIONI e EZTIONI, 2017, p. 32).

As tentativas pioneiras de desenvolvimento no campo interdisciplinar inteligência artificial e direito datam da década de 1980. Nesse período, que ficou conhecido como a primeira onda de ODR principal, os pesquisadores empreenderam esforços para produzir sistemas periciais, também denominados sistemas expert ou de representação (ANDRADE, CARNEIRO e NOVAIS, 2010, p. 3). Esses softwares objetivavam representar completamente os humanos na tomada de decisão vinculante. Pensava-se que seria possível traduzir todas as normas e os princípios de um sistema jurídico em proposições lógicas de linguagem de programação para dirimir todos os conflitos de uma sociedade. Algoritmos de sistemas expert selecionariam, em extensos bancos de dados de legislação e jurisprudência, as normas e os princípios aplicáveis às qualificações fáticas de cada caso concreto e produziriam a solução jurídica.

Um dos maiores projetos de sistema pericial foi posto em prática na década de 1980 no Reino Unido (LODDER e ZELEZNIKOW, 2005, p. 292). Um software foi desenhado por pesquisadores do Imperial College London para aplicar o British Nationality Act, julgando pedidos de concessão de cidadania britânica. Na concepção dos desenvolvedores, a tomada de decisão seria simples, pois os casos envolviam apenas uma regra básica: local de nascimento. Se o requerente tivesse nascido no Reino Unido, teria direito à cidadania. O projeto, contudo, foi considerado um fracasso e, em pouco tempo, abandonado. A realidade mostrou que 
as qualificações fáticas de um caso não são binárias e fechadas (nascido no Reino Unido, não nascido no Reino Unido), mas múltiplas e abertas. Se a pessoa tivesse nascido em Hong Kong ou nas Ilhas Malvinas, poderia seu local de nascimento ser considerado o Reino Unido? A resposta não era determinável com referência apenas ao British Nationality Act, mas dependia de tratados internacionais e negociações delicadas com China e Argentina.

$\mathrm{O}$ insucesso dos experimentos de sistemas periciais levou especialistas a concluir que o raciocínio jurídico não pode ser inteiramente transportado para a lógica matemática. A aplicação de programação lógica como ferramenta de construção de sistemas expert requer que as regras aplicáveis sejam imutáveis e monossêmicas. Tais características não podem ser atribuídas ao direito, subsistema social composto por normas jurídicas (regras e princípios) abertas à interpretação e à argumentação. A euforia inicial com a aplicação de IA à prática legal, no final dos anos 1990, deu lugar ao desapontamento (LODDER e ZELEZNIKOW, 2005, p. 295).

As ferramentas desenvolvidas nesse período, conquanto não tenham logrado êxito no alcance de autonomia total dos softwares na aplicação das leis, formaram a base de conhecimento para a segunda onda de tecnologia de ODR principal: os sistemas de apoio à decisão. Dessa vez, as expectativas dos pesquisadores eram menos audaciosas. Os novos projetos não objetivavam suprimir a atuação humana no processo de resolução do conflito, e sim qualificá-la. Sistemas de suporte à decisão são híbridos, buscam combinar as vantagens da tecnologia com o raciocínio jurídico humano (CARNEIRO et al., 2013, p. 790).

\section{O DEBATE ENTRE OS PARADIGMAS REPRESENTACIONISTA E FENOMENOLÓGICO}

A redução do entusiasmo nos sistemas periciais e o redirecionamento do foco para os sistemas de apoio à decisão marcaram a passagem da primeira para a segunda onda de tecnologia ODR principal. Essa transformação encontra ressonância no debate entre os paradigmas representacionista e fenomenológico que se acirrou ao final dos anos 1990 nos Estados Unidos, com a publicação de What Computers Still Can't Do, de Hubert Dreyfus, pela editora universitária do MIT. Não obstante o debate provocado por esse livro tenha causado significativo impacto nos projetos de inteligência artificial conduzidos no próprio MIT (CREVIER, 1993, p. 125), sua recepção por pesquisadores brasileiros dedicados ao tema no campo do direito foi praticamente inexistente. ${ }^{2}$

Hubert Dreyfus argumenta que a literatura de vanguarda sobre IA à época falhava em distinguir quatro tipos de atividade inteligente. A primeira área inclui "todas as formas de

2 Busca com as palavras-chave e operadores booleanos ("Hubert Dreyfus" E direito) no portal de periódicos da Capes encontrou zero resultados em português em 24.10.2020. 
comportamento associativo elementar em que significado e contexto são irrelevantes para a atividade em questão", como reconhecimento de padrões contra modelos fixos, dicionários mecânicos e rotinas de busca puramente baseadas em tentativa e erro (DREYFUS, 1999, p. 292). A segunda área "abrange mais o mundo conceitual do que o mundo perceptivo", e nela há a substituição da linguagem natural por uma linguagem formal para que "problemas [possam] ser completamente formalizados e completamente calculáveis", "do que o melhor exemplo é a lógica” (DREYFUS, 1999, p. 293). A terceira área “contém comportamentos que em princípio são formalizáveis mas, em verdade, são intratáveis” por "enumeração algorítmica exaustiva", como o jogo de xadrez (DREYFUS, 1999, p. 293). A quarta área "inclui todas as atividades cotidianas em nosso mundo humano que são regulares mas não governadas por regras", cujas técnicas de execução normalmente são "ensinadas através da generalização por exemplos e seguidas intuitivamente sem apelar a regras", e da qual o maior exemplo é a desambiguação das linguagens naturais (DREYFUS, 1999, p. 294).

Com base nessa tipologia, Dreyfus sustenta que, enquanto as atividades pertencentes às áreas I e II são afeitas à representação codificada, as pertencentes à área III são apenas parcialmente programáveis e as pertencentes à área IV são totalmente intratáveis (DREYFUS, 1999, p. 291). A impossibilidade de lograr uma análise exaustiva da razão humana como um conjunto de operações governadas por regras e elementos livres de contexto teria fundamento, para Dreyfus, na impossibilidade de simular, em uma máquina digital, as necessidades indeterminadas e a experiência de gratificação que geram o contexto em constante mutação do mundo humano (DREYFUS, 1999, p. 281-282).

As dificuldades de emular artificialmente o processamento de informação da mente derivariam do fato de que o senso de relevância dos humanos "é holístico e requer envolvimento na atividade em curso, enquanto representações simbólicas são atomistas e totalmente desligadas dessa atividade”. É o conhecimento de contexto comum (commonsense background understanding) que permite às pessoas "experimentar o que é atualmente relevante no trato com as coisas e pessoas como uma forma de saber-como (know-how)" (DREYFUS, 1999, p. xi). Essas habilidades, juntamente com "todos os interesses, sentimentos, motivações e capacidades corporais fazem um ser humano" e formam um "gigantesco e complexo sistema de crenças, [...] nossa compreensão pré-conceitual de contexto”. Tais características, ante todas as tentativas empreendidas no âmbito dos projetos de IA, parecem impossíveis de serem simbolicamente representadas e transmitidas a um computador (DREYFUS, 1999, p. xii).

$\mathrm{Na}$ reconstrução do contra-argumento feita por Dreyfus, os defensores do paradigma representacionista, ao tentarem representar todo o conhecimento em termos proposicionais como regras formais e atributos, pressupõem que a experiência humana é estruturada a partir do estoque de fatos livres de contexto e utilização de metarregras (DREYFUS, 1999, p. xxii). Compartilham a convicção de que a formalização completa do comportamento é possível com base na "suposição ontológica de que o mundo pode ser analisado em elementos lógicos independentes e na suposição epistemológica de que nossa compreensão do mundo pode ser 
reconstruída através da combinação desses elementos de acordo com regras heurísticas” (DREYFUS, 1999, p. 288).

Partindo de uma abordagem da intencionalidade baseada na fenomenologia de Heidegger e Merleau-Ponty, Dreyfus argumenta que, no espaço da experiência humana, "um objeto aparece a um participante não em isolamento e propriedades livres de contexto, mas como coisas que solicitam respostas por sua significação”. Parte significativa das decisões não é tomada com base em regras heurísticas, mas em sensitividades de contexto: "quando uma pessoa tem experiência suficiente para tornar-se um expert em um domínio determinado, o campo de experiência se torna estruturado de tal forma que a pessoa experimenta diretamente quais eventos e coisas são relevantes e como eles são relevantes" (DREYFUS, 1999, p. xxviii).

A representação do conhecimento a partir de elementos lógicos independentes e regras heurísticas exigiria sua reorganização sempre em referência a outras ordens de regras, mais gerais e formais, em um regresso infinito causado pela "necessidade de uma hierarquia de contextos em que um contexto mais alto ou mais amplo é usado para determinar a relevância e o significado dos elementos em um contexto mais baixo ou mais estreito" (DREYFUS, 1999 , p. 288). O conhecimento pré-conceitual e inarticulado do humano é o que interrompe essa necessidade de reorganização sem fim de fatos e regras. "Nossas necessidades, desejos e emoções", "que dependem das capacidades e vulnerabilidades de um corpo biológico socializado em uma cultura”, e "nos fornecem diretamente um senso de adequação de nosso comportamento", marcam a distinção irredutível entre a mente humana e o computador (DREYFUS, 1999, p. xlv).

Embora tenham se dedicado à aplicação da lógica deôntica - em especial a lógica deôntica paraconsistente proposta por Newton da Costa ${ }^{3}$ - na construção de sistemas especialistas legais, o trio de pesquisadores Aires José Rover, Cesar Serbena e José Renato Cella, que encabeçam a produção científica na área no Brasil, explicitam de forma bastante consciente os limites da formalização simbólica da linguagem natural para a resolução de conflitos jurídicos por sistemas principais periciais. As dificuldades reconhecidas pelos autores, conquanto estes não tenham se engajado diretamente com os argumentos avançados por Dreyfus, apontam para a conclusão que embasou a passagem da primeira para a segunda onda de ODR: de

3 "Lógica deôntica pode ser definida como uma espécie da lógica modal clássica com a introdução de operadores lógicos: O de obrigatório, $\mathrm{P}$ de permitido, $\mathrm{V}$ de proibido e $\mathrm{F}$ de indiferente" (DA COSTA, KRAUSE e BUENO, 2007, p. 898). "Lógica paraconsistente é a lógica de teorias inconsistentes mas não triviais. [...] Uma teoria é inconsistente se há uma fórmula (uma expressão gramatical bem-formada de sua linguagem) de tal modo que a fórmula e sua negação sejam ambas teoremas na teoria [...]. Uma teoria é trivial se todas as formas de sua linguagem são teoremas. A grosso modo, numa teoria trivial 'tudo' (expresso em sua linguagem) pode ser provado” (DA COSTA, KRAUSE e BUENO, 2007, p. 791). 
que a resolução de conflitos jurídicos, como atividade inteligente, será sempre apenas parcialmente formalizável.

Cella admite que "não integra o escopo da lógica a tarefa de prover decisões jurídicas e de estabelecer conteúdos" e concebe-a como um instrumento para esclarecer as noções de sistema normativo, lacunas, antinomias, distinção entre proposições normativas e normas (CELLA, 2008, p. 151). Rover reconhece que os sistemas especialistas legais "apresentam limitações no tratamento de problemas de elevada complexidade computacional e comportamental" (ROVER, 1999, p. 254), relacionados à característica geral da linguagem de se apresentar como "textura aberta, na qual o conteúdo normado não é suficientemente explícito", sendo "impossível prever-se antecipadamente todas as situações que podem ocorrer e a maneira de as regular" (ROVER, 1999, p. 202). Serbena enxerga "o texto legal [como] um fragmento da linguagem natural, acrescido de um vocabulário com significados específicos", cujo significado "geralmente é esclarecido mediante a consideração de sua inserção em uma frase ou expressão ou ainda em um contexto maior" (SERBENA, 2003, p. 44), e ressalta a importância do conhecimento não proposicional humano naquilo que denomina "questões de ordem pragmática e de contexto": "os fenômenos em geral não podem ser abordados por uma única perspectiva; eles podem ser expressos por diferentes vias e somente questões de ordem pragmática e de contexto podem decidir em última instância qual é a mais adequada expressão" (SERBENA, 2003, p. 160).

As limitações dos sistemas principais periciais em representar simbolicamente o conhecimento humano com base em elementos lógicos independentes e sua reconstrução de acordo com regras heurísticas - expressamente arguidas por Hubert Dreyfus e implicadas no tratamento dado ao tema por Aires José Rover, Cesar Serbena e José Renato Cella - motivaram o gradual redirecionamento das pesquisas e investimentos na área para sistemas de apoio à decisão, como ilustra o exemplo do British Nationality Act. Por essa razão, as seções seguintes deste artigo se restringem à descrição, a partir de fontes secundárias localizadas na revisão bibliográfica empreendida, de experiências de sistemas ODR principais de apoio à decisão, com foco no modo de funcionamento dos softwares e sua aplicação em conflitos jurídicos.

A parcela da literatura revisada que não trouxe dados primários ou secundários em profundidade a respeito de experiências concretas e do modo de funcionamento de sistemas de apoio à decisão, mas se dedicou à exposição da história e evolução das ferramentas de ODR (LIMA e FEITOSA, 2016), à reafirmação dogmática da relevância dos mecanismos de ODR para o acesso à justiça (FUJITA e ALMEIDA, 2019), à conclamação a uma adaptação cultural em favor da disseminação das técnicas de ODR (ZANFERDINI e OLIVEIRA, 2015) e à contextualização do tema em face da pandemia de COVID-19 (SOUZA NETTO, FOGAÇA e GARCEL, 2020), não foi, portanto, incluída nas seções que seguem. 


\section{EXPERIÊNCIAS DE SISTEMAS ODR PRINCIPAIS DE APOIO À DECISÃO}

O desenvolvimento de ODR principais de auxílio à decisão passou por diferentes momentos e fontes majoritárias de financiamento (BRAEUTIGAM, 2006, p. 281). Na primeira fase, apenas universidades e centros de pesquisa financiavam projetos experimentais; na segunda, empresas passaram a investir em ODR e a patentear soluções comercializáveis; e na terceira, em curso, tem crescido o interesse em parcerias público-privadas para a institucionalização e o aprimoramento de ODR.

Sistemas ODR de apoio à decisão executam funções variadas e são empregáveis em procedimentos de negociação, mediação, conciliação, arbitragem e até mesmo no processo judicial. Nesta seção, será descrito o modo de funcionamento de algumas experiências de tecnologias de ODR principais de suporte, com base em fontes secundárias localizadas a partir de revisão bibliográfica da produção nacional e internacional sobre o tema.

\section{I. MODELO DE NEGOCIAÇÃo DE LODDER-ZELEZNIKOW}

O modelo Lodder-Zeleznikow, embora tenha sido inicialmente projetado para negociação, pode ser adaptado para procedimentos de mediação e conciliação. Ele combina as ferramentas de raciocínio dialógico concebidas por Arno Lodder com as técnicas automatizadas de maximização de utilidade desenvolvidas por John Zeleznikow com base na teoria dos jogos.

O modelo se apoia nos conceitos da teoria da negociação por princípios, também chamada de negociação baseada em interesses ou negociação integrativa. Essa concepção se diferencia da distribuição distributiva, em que o problema a ser resolvido é a distribuição de um conjunto fixo de itens de modo a maximizar a satisfação das partes. Negociações distributivas são jogos de soma zero ou trocas ganha-perde. Suas duas propriedades fundamentais são utilidade e resistência. Utilidade é o valor que cada parte atribui a um item, enquanto resistência é a propensão da parte de alterar a utilidade de um item (CARNEIRO et al., 2013, p. 793).

Em negociações integrativas, as partes negociam para obter algo que não poderiam obter de outro modo. São jogos de soma não zero ou trocas ganha-ganha, pois se espera que o problema tenha mais soluções do que se imaginava a princípio. As partes tentam trazer para a mesa o maior número possível de itens sobre os quais negociar, a fim de alcançar o equilíbrio de Nash ou ótimo de Pareto, em que a situação de todas as partes após a negociação é melhor do que sua situação anterior (CARNEIRO et al., 2013, p. 794).

A negociação por princípios é orientada por cinco diretrizes (CARNEIRO et al., 2013, p. 794): separe as pessoas do problema; foque nos interesses, não nas posições; invente opções para ganho mútuo; insista em critérios objetivos; e conheça sua melhor alternativa à negociação do acordo (MANA). Além da MANA, são importantes também os conceitos de pior alternativa à negociação do acordo (PANA), mais provável alternativa à negociação do acordo (MPANA) e zona de possível acordo (ZOPA). 
Lodder e Zeleznikow (2005, p. 290) propõem uma negociação em três passos: (1) o sistema informa a cada parte, de maneira confidencial, quais são as suas MANA, PANA e MPANA; (2) o sistema fornece um canal de comunicação para as partes trocarem proposições justificadas; e (3) o sistema sugere ofertas-pacote com base em um algoritmo de alocação de pontos.

Imagine-se a situação fictícia de partilha de bens no processo de divórcio de Antônio e Claudia, sem prole e sob o regime de comunhão parcial. ${ }^{4} \mathrm{O}$ conjunto dos bens comuns do antigo casal perfaz uma casa, um apartamento, um carro e determinada quantidade de títulos mobiliários. No início da negociação, cada parte insere no sistema, em um questionário confidencial, quais são seus interesses e objetivos. Claudia pode expressar, por exemplo, preferência pela casa, por ter localização mais próxima de seu trabalho, e pelas ações, por acreditar que irão valorizar em breve. Antônio pode manifestar desejo de permanecer com o apartamento, por querer habitar em um imóvel menor, e pelo carro, por necessitar do veículo para visitar seus pais no interior aos finais de semana. Além de interesses e objetivos, as partes munem o sistema com a maior quantidade possível de informações relevantes para a resolução da controvérsia.

É importante observar que o sistema não qualifica juridicamente os fatos. Se houver discordância acerca da autenticidade de uma escritura imobiliária ou da necessidade de pagamento de pensão alimentícia, por exemplo, as partes devem confiar a decisão sobre aquele fato específico a um terceiro neutro. É possível aprimorar a tecnologia do sistema para reconhecer evidências e analisar documentos, mas há limitações intransponíveis. A assistência de um profissional do direito, pois, é essencial em todo o processo.

A seguir, o sistema consulta sua base de dados de casos e regras, a fim de identificar qual seria o resultado mais provável em um processo judicial (PMANA), assim como as melhores e piores alternativas à negociação do acordo por cada parte (MANA e PANA). Isso ajuda a evitar que a parte aceite um acordo que deveria rejeitar ou rejeite um acordo que seria aconselhável aceitar. O cálculo da PMANA, MANA e PANA pode ser feito por técnicas de mineração de dados ou tecnologia de web semântica a partir de um raciocínio baseado em regras e casos armazenados ou indexados no banco de dados do sistema (LODDER e ZELEZNIKOW, 2005, p. 326).

Para inferir o que aconteceria se as duas partes envolvidas na disputa tivessem a matéria resolvida por um juiz, o sistema seleciona em sua base de jurisprudência os casos mais similares e deles extrai três dados: a descrição do problema (estado inicial da situação), a solução adotada (lista de passos dados para resolver o problema) e o resultado (estado final da situação).

4 A situação fictícia é de elaboração própria dos autores com base em informações dispostas pela literatura secundária referenciada a respeito do funcionamento do modelo de Lodder-Zeleznikow. O objetivo de sua utilização é facilitar a compreensão da aplicação desse sistema principal de apoio à decisão em um conflito. 
Cada caso é uma unidade básica de informação, uma experiência passada, um pedaço contextualizado de conhecimento. As similaridades são sempre parciais (inexistem casos idênticos), e para cada uma é atribuído um peso diferente. É possível refinar a seleção dos casos a partir de critérios específicos, como normas invocadas, órgão decisor e ano de julgamento (CARNEIRO et al., 2013, p. 798).

Uma vez conscientes de desfechos realistas pela via do litígio, as partes dão o segundo passo no processo de negociação, iniciando um diálogo por mensagens de texto. O objetivo dessa fase é fazer com que as partes se comuniquem de forma eficaz, justificando suas proposições com critérios objetivos e buscando entender o lado do outro. A plataforma de troca de mensagens é configurada de modo a incentivar as partes a expressarem não apenas suas posições, mas seus interesses e argumentos. Claudia pode digitar "eu quero a casa” e Antônio, "eu quero o carro". Sentenças posicionais como essas dificilmente persuadem e geram empatia na outra parte, dificultando a obtenção de consenso. O sistema instiga a exposição dos verdadeiros motivos por trás das preferências. Reagindo à provocação do sistema para que fundamente sua proposição, Claudia pode acrescentar "pois a localização é mais próxima do meu trabalho" e Antônio, "porque preciso utilizá-lo para visitar meus pais no interior aos finais de semana”.

As partes podem configurar o sistema para alterar a ordem das fases, pulando diretamente para a etapa da alocação de pontos. Todavia, os autores recomendam que a sequência de passos seja observada (LODDER e ZELEZNIKOW, 2005, p. 324). O sucesso na obtenção do consenso está diretamente relacionado à capacidade das partes de compreenderem as necessidades uma da outra. Além disso, a troca de proposições fundamentadas as leva a refletir mais profundamente sobre seus próprios interesses, evitando que a alocação de pontos subsequente seja feita de forma imponderada. Uma negociação presencial também segue esta ordem: a etapa de compartilhamento de informações antecede a de geração de propostas.

Se as partes não chegarem a um acordo na fase de diálogo, o sistema dá início à terceira fase do processo e as convida a alocar, de forma secreta, um total de 100 pontos entre os itens sob disputa. O padrão de distribuição de pontos determina o critério de utilidade de cada parte. Suponha-se que Claudia atribuiu 40 pontos à casa, 10 ao carro, 20 ao apartamento e 30 às ações, e Antônio distribuiu 15 pontos à casa, 25 ao carro, 45 ao apartamento e 15 às ações. Na sequência, o sistema submete os pontos das preferências a uma manipulação matemática que aloca para cada parte a metade mais valiosa de acordo com a sua própria avaliação. Cada parte recebe ao menos 50\% dos itens desejados e em alguns casos até mais, em razão da diferença de percepção subjetiva sobre os valores dos itens.

A alocação de pontos se assenta em três premissas: a disputa pode ser modelada usando a negociação por princípios; pesos podem ser atribuídos para cada um dos itens em disputa; e há número de itens suficientes para compensar as partes pela perda de um item (LODDER e ZELEZNIKOW, 2005, p. 313). Duas regras contraintuitivas, derivadas da experiência dos 
desenvolvedores do método, orientam o procedimento de distribuição: quanto mais itens em disputa, mais fácil a negociação; e a divisão deve começar pelo item em que as partes têm maior diferença de utilidade (uma quer muito, outra nem tanto).

O algoritmo de alocação de pontos, denominado Adjusted Winner, realiza a distribuição em duas etapas: a fase do vencedor e a fase do ajustamento (CAFÉ et al., 2010, p. 6). Na primeira, cada item vai para a parte que mais pontos a ele atribuiu. Na segunda, os itens são fracionados conforme uma hierarquia de decomposição (itens menos disputados são divididos primeiro), até que as partes tenham o mesmo número de pontos. Sob essa lógica, o sistema proporia ao casal em divórcio a seguinte sugestão de acordo: Claudia fica com a casa e as ações, totalizando 70 pontos de utilidade, e Antônio, com o apartamento e o carro, em nível idêntico de satisfação. A diferença nas preferências subjetivas das partes sobre os itens faz com que o bolo cresça antes de ser dividido.

Entretanto, nem sempre há diferença significativa de preferência ou perfeita simetria de informação entre as partes. Quanto maior a dificuldade dos disputantes em gerar valor, mais acirrado é o conflito distributivo. Além disso, uma divisão por pontos equitativa pode conduzir a uma divisão monetária desigual quando há disparidade no nível de informação ou vulnerabilidade entre as partes. Estudos empíricos sobre o emprego do algoritmo Advanced Winner em divórcios na Austrália constataram que mulheres tendem mais a aceitar acordos desvantajosos para abreviar o conflito do que homens (LODDER e ZELEZNIKOW, 2005, p. 335).

Com o intuito de suprir a distorção entre a alocação por pontos e a alocação monetária, o algoritmo foi alterado (CAFÉ et al., 2010, p. 8). Na nova versão, apelidada de Adjusted Winner By Value, a fase do vencedor permanece igual, e na fase do ajustamento a divisão é feita para igualar não os pontos, mas o valor monetário dos itens. A alocação de pontos mediante o conhecimento prévio do valor monetário dos bens impede que uma parte tire proveito da outra e permite uma distribuição mais genuinamente associada às preferências subjetivas de cada parte. De acordo com esse critério, e supondo que o valor de mercado da casa tenha sido avaliado em 300 mil reais, o do apartamento, em 250 mil, o do carro, em 50 mil, e o das ações, em 20 mil, o sistema sugeriria que Claudia ficasse com a totalidade da casa e 10 mil reais em ações, e Antônio, com a totalidade do apartamento e do carro e 10 mil reais em ações.

As partes podem elaborar novas propostas com base na primeira sugestão feita pela plataforma. Nesse caso, elas submetem, simultânea e confidencialmente, um número limitado de ofertas pacote ao sistema, que detecta a existência de uma zona de possível acordo (ZOPA) entre elas. Se houver uma diferença igual ou inferior a um percentual previamente determinado pelas partes, o sistema divide o intervalo ao meio e traz o valor como sugestão de acordo.

Esse método, também conhecido como oferta cega (blind bidding), preserva o sigilo das propostas iniciais, impedindo a revelação do ponto de reserva das partes (valor mínimo pelo 
qual um lado está disposto a fechar o acordo), e desfaz o dilema da primeira oferta. ${ }^{5}$ O sistema pode, ainda, identificar as preferências iniciais das partes para gerar novas ofertas pacote mais propensas de aceitação (BRAEUTIGAM, 2006, p. 285).

Além da opção pela submissão de novas propostas pacote, as partes podem escolher retornar à fase dialógica para retomar a comunicação, repetir o procedimento de alocação de pontos ou abandonar a negociação. Mesmo que não se chegue a um consenso sobre todos os itens sob disputa, a troca de proposições fundamentadas, os resultados da distribuição de pontos e a sucessão de propostas propiciados pelo método Lodder-Zeleznikow são um ponto de partida no tratamento do conflito e podem ser aproveitados na continuação da resolução da controvérsia por outro método.

\subsection{UMCOURT}

Uma das principais críticas às tecnologias de ODR é que parte da informação relevante para a resolução da disputa se perde, por se dar a comunicação entre as partes apenas por vias digitais. Processos comunicativos são responsivos: a forma como um interlocutor reage às emoções veiculadas pela linguagem corporal do outro influencia diretamente na qualidade do tratamento do conflito. Essa assertiva é verdadeira especialmente para métodos consensuais de solução de controvérsias, em que a construção de vínculo de confiança entre as partes constitui requisito para um desfecho bem-sucedido.

Com o objetivo de minimizar essa fragilidade, um grupo de pesquisadores da Universidade do Minho, em Portugal, desenvolveu uma nova abordagem de ODR que utiliza inteligência de ambiente para detectar emoções, estilos pessoais de lidar com conflito e níveis de estresse das partes. O software UMCourt, cujo modo de funcionamento se assemelha ao do modelo Lodder-Zeleznikow e que já vinha sendo testado na Universidade do Minho no tratamento de conflitos trabalhistas, de família e sucessórios, foi integrado ao software VirtualECare, plataforma de leitura do ambiente de resolução do conflito. Os desenvolvedores do projeto partiram da premissa de que a perda de informação em ODR ocorre não pelo fato de ser o suporte de comunicação digital, mas por ser majoritariamente textual (CARNEIRO et al., 2017, p. 1).

O sistema VirtualECare produz, em tempo real e por meio de métodos não invasivos, três tipos de informação ambiental sobre as partes: emoções, estresse e estilo pessoal de negociação (CARNEIRO et al., 2017, p. 2). A coleta desses dados é útil principalmente em procedimentos

5 Colocar a primeira proposta na mesa pode trazer à parte proponente o benefício do ancoramento (a negociação tenderá a não se afastar em demasia do valor âncora inicial) ou, caso se tenha pouca informação sobre o ponto de reserva da outra parte, o risco de fazer uma oferta muito desvantajosa para si. A vantagem da oferta cega é o fato de que, se as partes não chegarem a um acordo, as ofertas não são reveladas à outra parte (WANG, 2009, p. 48). 
de mediação e conciliação guiados por um terceiro neutro humano em que as partes se encontram a distância. As intervenções do mediador ou do conciliador ao longo da sessão serão mais eficazes para facilitar a resolução da disputa em função da posse de informação contextualizada sobre o comportamento das partes.

A classificação do estilo de resolução do conflito das partes feita pelo sistema se baseia nas categorias propostas por Thomas e Kilmann (2008, p. 3). Segundo esses autores, diferentes combinações entre as dimensões assertividade e cooperação geram cinco tipos de comportamento humano diante de situações de conflito: competição, colaboração, concessão, evitação e acomodação. Um indivíduo competitivo é assertivo e não cooperativo, persegue seus interesses às custas das necessidades do outro. Uma pessoa colaborativa é, ao mesmo tempo, assertiva e cooperativa, tenta encontrar uma solução que satisfaça os interesses da outra sem abrir mão dos seus próprios. A atitude concessiva exprime um nível intermediário de assertividade e cooperação; tipicamente, busca um meio-termo e não se engaja tanto na resolução do problema. A parte que evita conflitos não é assertiva nem cooperativa, pois não tenta satisfazer seus interesses nem os da outra pessoa, mas tão somente adiar o tratamento do conflito. O estilo acomodado é não assertivo e cooperativo; negligencia suas próprias necessidades para atender às do outro.

O software VirtualECare categoriza o estilo pessoal de cada parte com base nas propostas trocadas no processo de negociação (CARNEIRO et al., 2017, p. 3). Uma oferta acima da MANA da parte proponente e abaixo da PANA da parte receptora é considerada competitiva. Uma oferta abaixo da PANA da parte proponente e acima da MANA da parte receptora é considerada acomodada. Uma oferta dentro da ZOPA, mas mais próxima da MANA da parte proponente e da PANA da parte receptora, é considerada colaborativa. Uma oferta dentro da ZOPA, mas mais próxima da PANA da parte proponente e da MANA da parte receptora, é considerada concessiva. Não fazer propostas ou ignorar as propostas feitas pela outra parte é considerado evitação.

O método de classificação é dito não invasivo, pois não exige que as partes preencham questionários extensos e abstratos, prática comum na maioria dos testes de comportamento. Como muitos negociadores alteram o estilo de negociação no evoluir da sessão, o sistema identifica uma tendência principal e outra secundária de cada parte, assim como uma estratégia de intercalação de estilos.

O nível de estresse e as emoções das partes são identificados a partir de sinais fisiológicos, como o padrão, a intensidade e a duração do toque em telas touchscreen e a quantidade e a aceleração do movimento, capturadas por câmeras de vídeo. Essas formas de coleta também são vistas como não invasivas, pois, além de serem utilizadas apenas mediante o consentimento prévio e informado das partes, não requerem aparelhos de interface adicionais aos que normalmente já seriam empregados no procedimento virtual (CARNEIRO et al., 2017, p. 5).

A integração entre os softwares UMCourt e VirtualECare objetiva enriquecer a comunicação entre as partes, e entre as partes e o terceiro neutro, em um procedimento de mediação 
ou conciliação virtual. Além de ampliar a diversidade de canais de troca de informação, adicionando as funcionalidades vídeo e áudio, o sistema mune o mediador ou conciliador de dados relevantes para orientar sua atuação como facilitador na resolução do conflito.

\subsection{OUTRAS EXPERIÊNCIAS}

Além do algoritmo Adjusted Winner, utilizado na resolução de casos de direito de família e sucessório na Austrália (ANDRADE, CARNEIRO e NOVAIS, 2010, p. 26), e do software UMCourt, empregado no tratamento de conflitos comerciais, trabalhistas, de família e sucessórios em Portugal (CAFÉ et al., 2010, p. 4), outras experiências de aplicação prática de sistemas ODR merecem menção.

A plataforma Resolution Center, desenvolvida pela empresa de comércio virtual eBay, resolve mais de 60 milhões de disputas B2C (business to consumer, ou entre comerciante e consumidor) por ano (SELA, 2018, p. 93). Diante de um problema na compra de produtos pelo site, o consumidor preenche um questionário que cumpre o papel de um conciliador: coleta informação factual, identifica preferências e sugere opções de resolução. O algoritmo detecta padrões de surgimento de disputas (a maior parte dos casos diz respeito a atraso na entrega ou defeito no produto) e de resolução (devolução de parte do valor pago ou reposição da mercadoria, por exemplo), que alimentam uma árvore de decisão. Em 90\% dos casos, as partes aceitam o resultado sugerido pelo sistema. Nos outros $10 \%$, a disputa é levada à decisão de um humano, que arbitra a controvérsia de posse das informações já produzidas pelo sistema na fase automatizada anterior (SELA, 2018, p. 103). A autorreferencialidade das decisões tomadas na plataforma (o valor de uma disputa é fixado em referência às disputas anteriores) e a centralidade que o mecanismo reputacional de feedback assume para transações futuras (conflitos não resolvidos podem transformar-se em notas baixas para os participantes) conduzem à caracterização do eBay "como uma jurisdição em si mesma” e à resolução de litígios de comércio virtual em seu âmbito como "eBay law" (KATSH, RIFKIN e GAITENBY, 2000, p. 729 e 731).

Empresas não são os únicos atores sociais engajados na implementação de tecnologias ODR. A institucionalização de soluções ODR por Estados tem aumentado na última década. O incentivo a métodos ODR por órgãos governamentais parte do reconhecimento de que os crescentes fenômenos de globalização e digitalização têm alterado a dinâmica das relações sociais e das tensões delas emergentes, impulsionando, por consequência, mudanças em seus mecanismos de pacificação.

Além disso, a regulamentação das técnicas de ODR por Estados evita que o vácuo normativo na matéria desloque ainda mais o movimento de desformalização dos mecanismos de resolução de disputas para a regulação privada transnacional (ARBIX, 2015, p. 222). Organizações supranacionais, cujo poder relativo rivaliza com o poder soberano de alguns Estados, têm tomado a dianteira da mobilização a favor dos mecanismos de ODR. Ao perder protagonismo na regulação dos métodos de pacificação de conflitos sociais para entes privados 
internacionais, governos aceleram o processo de transição gradual do poder da esfera centralizada nacional para a descentralizada supranacional.

O governo do Reino Unido adotou duas plataformas de resolução de conflitos, Money Claim Online e Traffic Penalty Tribunal, implementadas em 2017 e 2014, respectivamente. Ambos os sistemas são de submissão voluntária, isto é, a parte escolhe se prefere submeter seu caso pelas ferramentas digitais ou seguir pelo processo judicial ou administrativo tradicional.

A Money Claim Online consiste em um sistema judicial virtual projetado para causas de valor fixo e inferior a 100 mil libras esterlinas, que envolvam apenas um requerente e um requerido, ambos legalmente capazes e domiciliados no Reino Unido. O requerente tem o limite de 1.080 caracteres para explicar por que faz jus ao recebimento daquela quantia. $\mathrm{O}$ requerido é notificado por correio e envia sua defesa, normalmente produzida com a ferramenta de preenchimento automático do formulário de resposta do sistema, que já oferece as opções de contestação mais comuns (pagamento já efetuado, divergência quanto ao valor do débito, entre outras). As partes podem acordar em levar o caso para a mediação presencial. Caso contrário, a disputa é julgada por um juiz na corte de pequenas causas (HM COURTS \& TRIBUNALS SERVICE, 2017, p. 4).

O Traffic Penalty Tribunal é um sistema administrativo virtual voltado à interposição de recursos contra penalidades de trânsito. A plataforma restringe as matérias que podem ser alegadas para cada tipo de ilícito. O recorrente pode fazer o upload de provas documentais de diferentes suportes (vídeo, áudio, imagem, texto). A autoridade administrativa decisora pode solicitar uma ligação telefônica com o recorrente, e a decisão é prolatada no próprio sistema (REINO UNIDO, 2014, p. 1).

A Comissão das Nações Unidas para o Direito Comercial Internacional (UNCITRAL, sigla para United Nations Commission on International Trade Law) publicou em 2017 uma nota técnica sobre a resolução on-line de disputas, em que recomenda aos Estados-membros da Organização das Nações Unidas (ONU) que implementem sistemas ODR para dirimir conflitos oriundos de transações comerciais transnacionais de baixo valor (UNCITRAL, 2017, p. 9). Em 2013, a União Europeia (UE) aprovou o Regulamento n. 524/2013 sobre resolução de litígios em linha em matéria de consumo, cujo âmbito de aplicação abrange a "resolução extrajudicial de litígios relativos a obrigações contratuais derivados de contratos de compra e venda ou de prestação de serviços celebrados em linha entre um consumidor residente na União e um comerciante estabelecido na União" (UE, 2013, p. 1). Embora a territorialidade do regulamento exclua o acesso a consumidores residentes em outras regiões (ALBORNOZ, 2019, p. 4142), a criação de uma plataforma de ODR no âmbito da UE, prevista no regulamento, representa um avanço para aumentar a confiança em transações comerciais transfronteiriças dentro do bloco e fortalecer o mercado interno (VIÑALS, 2014, p. 398).

A Internet Corporation for Assigned Names and Numbers (ICANN), organização sem fins lucrativos que coordena o principal sistema global de domínio de nomes e números de 
endereços de internet, emitiu em 2009 uma recomendação de boas práticas de ODR, baseando-se em padrões aconselhados por outras nove instituições de influência regional ou mundial (ICANN, 2009, p. 1). O procedimento para dirimir conflitos de propriedade intelectual em torno de um domínio de nome registrado, no âmbito do ICANN, é regido pela Uniform Domain Name Dispute Resolution Policy (UDPR). Em razão da especialização temática, circunscrita a alegações e contestações padronizadas em matéria de domínio de nome registrado, as decisões são proferidas em média após 45 a 60 dias da submissão do pedido inicial (BENYEKHLEF e GÉLINAS, 2005, p. 126). Além disso, a execução da decisão é, em termos práticos, automática. A ICANN tem controle sobre todas as empresas responsáveis por registrar nomes nos domínios com sufixos genéricos, tais como “.com”, “.net” e “.org”, e, portanto, obriga-as contratualmente à aplicação da UDPR (BENYEKHLEF e GÉLINAS, 2005, p. 4).

\section{ACESSo À JUSTiÇA, JustiçA PROCEDimental e JustiçA de Resultados}

A principal preocupação que as tecnologias de ODR suscitam é como assegurar que em uma resolução digital de conflito seja feita justiça. Reflexões sobre justiça no âmbito de ODR abrangem geralmente três aspectos: acesso à justiça, justiça procedimental e justiça de resultados (EBNER e ZELEZNIKOW, 2015, p. 152).

Gradualmente tem se dissociado, no Brasil, acesso à justiça de acesso ao processo ou ao Judiciário. A concepção de justiça multiportas, que designa para cada tipo de litígio o método mais adequado de resolução, aos poucos se torna o novo paradigma institucional a ser alcançado. ${ }^{6}$ Sob essa perspectiva plural, mecanismos eficientes de ODR podem viabilizar mais acesso à justiça, por darem resposta a conflitos que, por suas peculiaridades, dificilmente seriam levados aos meios de resolução tradicionais (ARBIX, 2015, p. 221). Manter o caráter de voluntariedade das ferramentas ODR ou fornecer as ferramentas em ambientes públicos, como juizados especiais, impede que sua implementação se traduza em menor acesso à justiça para os mais de 60 milhões de excluídos digitais brasileiros ${ }^{7}$ (IBGE, 2016, p. 6).

6 O Índice de Conciliação do Poder Judiciário brasileiro, que reflete o percentual de sentenças homologatórias de acordo proferidas, comparativamente ao total de sentenças e decisões terminativas, foi, no ano-base 2017, 12,1\%, apenas 1 ponto percentual superior em relação ao ano-base de 2015 (CNJ, 2018a, p. 137). A terceira meta nacional do Poder Judiciário para 2019 é aumentar o número de casos solucionados por conciliação na Justiça Federal em 5\% e na Justiça Estadual em 2\% (CNJ, 2018b, p. 2).

7 Aproximadamente $30 \%$ dos brasileiros não têm acesso à internet em casa, segundo a Pesquisa Nacional por Amostra de Dados Contínua do IBGE de 2016 (p. 6) e a última publicação da pesquisa Global Digital Report (2018, p. 31). 
A justiça procedimental, por sua vez, traz exigências de natureza formal e se expressa, em cada método de resolução de conflito, por um conjunto de princípios. Aos litigantes no processo judicial são garantidas a persuasão racional do juiz e a motivação das decisões judiciais, por exemplo. Aos participantes da mediação e conciliação, tanto na esfera judicial quanto na extrajudicial, são asseguradas a confidencialidade e a autonomia da vontade das partes, assim como outras garantias. A arbitragem se pauta no livre convencimento do árbitro e na obrigatoriedade da cláusula arbitral, entre outros princípios. Comum a todos os procedimentos é o direito constitucional do devido processo legal, que se desdobra na imparcialidade do terceiro (seja ele juiz, mediador, conciliador ou árbitro) e na isonomia das partes. Diante disso, um dos desafios para a regulação de ODR no Brasil é submetê-las aos princípios constitucionais e infraconstitucionais regentes de cada subsistema procedimental (litígio, mediação, conciliação e arbitragem).

Justiça de resultados provoca discussões sobre a indisponibilidade de certos tipos de direitos, a necessidade de segurança jurídica e a prevalência de normas de ordem pública, incluindo as voltadas à proteção de terceiros de boa-fé e partes vulneráveis, como consumidores e empregados (ARBIX, 2015, p. 222). O esforço regulatório sobre os mecanismos de ODR deve determinar o grau de transparência a ser exigido da plataforma, ou seja, o nível de detalhamento do passo a passo seguido pelo algoritmo para chegar à decisão. Quanto maior a opacidade do sistema, mais difícil verificar se foram aplicadas as normas corretas ao caso ou se houve o cometimento de injustiça material. Códigos não são neutros, sem supervisão humana podem reproduzir vieses discriminatórios (SELA, 2018, p. 141).

A fim de medir a percepção subjetiva de justiça procedimental das partes em métodos ODR comparativamente a procedimentos ADR tradicionais, um grupo de pesquisadores da Faculdade de Direito da Universidade de Stanford realizou em 2018 um experimento com 86 pessoas (SELA, 2018, p. 130). O experimento analisou como as partes percebiam justiça procedimental sob os aspectos controle sobre o processo, controle sobre a decisão, justiça na interação (ser tratado com isonomia, dignidade e respeito) e justiça na informação (receber explicações sobre o processo). Todas as informações acerca do procedimento são secundárias e foram obtidas a partir de fontes secundárias localizadas na revisão bibliográfica empreendida.

Três hipóteses foram testadas pelos pesquisadores condutores do experimento. A primeira é a hipótese do ajuste de expectativas, segundo a qual um software mediador resulta em mais experiências procedimentais de justiça do que um mediador humano (SELA, 2018, p. 111). A assertiva se fundamenta em quatro aportes teóricos: o princípio do design de audiência (agentes intuitivamente adaptam a comunicação ao perfil do ouvinte), a teoria da riqueza da mídia (meio linear de comunicação é menos apropriado para tarefas como resolução de conflitos, que envolvem ambuiguidade, alta interdependência e conteúdo emocional), a teoria da presença social (mídia linear limita a habilidade das partes de criar presença social, se projetar e perceber outros como reais) e a teoria dos computadores como atores sociais (características 
antropomórficas mínimas em computadores despertam nos humanos padrões de interação semelhantes aos que mantêm entre si). A hipótese afirma que as partes ingressam em uma mediação facilitada por software com menos expectativas e menor confiança, o que resulta em maior satisfação ao final.

A segunda hipótese testada é a da subordinação relutante, de acordo com a qual um árbitro humano resulta em mais experiências de justiça procedimental do que um software árbitro (SELA, 2018, p. 115). A arbitragem por ODR principal encontra resistência, pois contraria a percepção de que justiça e equidade são traços distintamente humanos, que não podem ser imitados nem mesmo pelo mais inteligente software. Predomina o entendimento de que, apesar de serem dotados de tecnologias de linguagem natural, reconhecimento de fala e processamento de imagem, softwares não conseguem raciocinar e decidir como humanos, por ser muito difícil traduzir princípios e conceitos de justiça em proposições lógicas.

A terceira hipótese posta à prova é a da tecnologia consistente, que postula que em processos med-arb (inicia-se com a mediação e evolui para a arbitragem) as partes reportam mais experiências de justiça procedimental quando ambos os procedimentos utilizam o mesmo tipo de tecnologia, seja ele principal, seja instrumental (SELA, 2018, p. 119).

Os participantes do experimento foram submetidos a procedimentos de mediação e arbitragem em uma plataforma virtual, desempenhando o papel de compradores em um conflito consumerista fictício. As partes foram previamente informadas se o terceiro neutro (mediador ou árbitro) do procedimento era humano (ODR instrumental) ou um software (ODR principal). Ao final das sessões, os participantes preencheram questionários que mensuravam suas percepções de justiça procedimental (SELA, 2018, p. 123).

Todas as hipóteses foram confirmadas, e apenas a terceira sofreu uma pequena adaptação (SELA, 2018, p. 132). Constatou-se redução da percepção de justiça procedimental apenas nas sequências mediação com ODR instrumental e arbitragem com ODR principal, reforçando a hipótese da subordinação relutante. O resultado da experiência atestou, portanto, que a determinação do tipo mais adequado de tecnologia depende do papel exercido pelo terceiro: se facilitar a interação, sistemas ODR são mais apropriados; se fornecer um resultado vinculante, softwares instrumentais se mostram mais propícios. Indicou-se, contudo, que a percepção subjetiva das partes não pode ser o único critério utilizado para aferir justiça procedimental e servir de base a prescrições regulatórias dos mecanismos de ODR, pois situações de assimetria de informação e vulnerabilidade entre as partes podem levar altos níveis de satisfação a encobrirem injustiças de resultado.

\section{CONCLUSÃo}

Métodos de resolução digital de controvérsias são uma categoria guarda-chuva que abriga a aplicação de tecnologia à prática jurídica em diferentes níveis de complexidade e automação. Enquanto sistemas instrumentais empregam tecnologias mais simples de informação e 
comunicação, sistemas principais contam com agentes de inteligência artificial capazes de sugerir decisões. Softwares expert, cujo escopo é traduzir normas e princípios de um sistema jurídico em proposições lógicas, mostraram-se falhos. Conscientes da imprescindibilidade do raciocínio humano na aplicação do direito, os especialistas se voltam atualmente à produção de sistemas de suporte, que objetivam elevar a qualidade do processo de tomada de decisão.

Os mecanismos de ODR são especialmente apropriados para a resolução de disputas oriundas de relações consumeristas eletrônicas massificadas, de baixo valor e transnacionais, mas sua utilidade vai além. Sistemas de apoio à decisão têm sido implementados com sucesso nos domínios do direito de propriedade intelectual, família, sucessões e administrativo.

Empresas multinacionais de comércio virtual, como o eBay, foram as pioneiras na adoção de plataformas ODR em larga escala. Já há, contudo, países de common law, a exemplo do Reino Unido e da Austrália, e civil law, como a maior parte dos Estados-nações pertencentes à UE, que integraram ferramentas de ODR em seus sistemas judiciais e administrativos. Em paralelo à pouca atenção que a maioria dos Estados têm conferido às tecnologias de ODR, observa-se um movimento de regulação transnacional pela UE e pela ONU, por meio de sua comissão UNCITRAL, e por entes privados, como a ICANN.

As tecnologias de ODR, além de possibilitarem economias de escala nos quesitos tempo e dinheiro em virtude da automação de parte do processo decisório, podem aumentar o acesso à justiça. Ao darem vazão a conflitos consumeristas massificados e de baixo valor, cujo deslinde, em termos proporcionais, interessa mais às classes sociais de menor renda, os mecanismos de ODR trazem consigo a possibilidade de tornar a justiça mais cidadã e inclusiva.

A principal desvantagem associada ao uso de ODR é a transferência relativa de autoridade dos seres humanos para algoritmos no tratamento dos conflitos sociais. Tal problema pode ser minorado com uma regulação das técnicas de ODR que as submeta à supervisão humana e garanta que pressupostos de acesso à justiça, justiça procedimental e justiça de resultado sejam satisfeitos.

\section{AGRADECIMENTOS}

A autora agradece a Ricardo Spindola pela atenciosa leitura e pelos valiosos comentários. Eventuais erros e omissões são de responsabilidade da autora.

\section{REFERÊNCIAS}

ALBORNOZ, Maria Mercedes. Online dispute resolution (ODR) para el comercion electrónico en clave brasileña. Direito UnB, v. 3, n. 1, p. 25-51, set./dez. 2019. 
ANDRADE, Francisco; CARNEIRO, Davide; NOVAIS, Paulo. A inteligência artificial na resolução de conflitos em linha. Scientia Ivridica, v. LIX, n. 321, p. 1-28, 2010.

ARBIX, Daniel do Amaral. Resolução on-line de controvérsias: tecnologia e jurisdições. Tese (Doutorado) - Programa de Pós-Graduação em Direito da Universidade de São Paulo, São Paulo, 2015.

BENYEKHLEF, Karim; GÉLINAS, Fabien. Online Dispute Resolution. Lex Eletronica, v. 10, n. 2, p. 1 $-129,2005$.

BRAEUTIGAM, Andrea. Fusses that fit online: online mediation in non-commercial contexts. Appalachian Journal of Law, v. 5, p. 275-301, 2006.

BRANNIGAN, Colm. Online dispute resolution. CCH Canadian, v. 54, p. 6901-6953, 2007.

CAFÉ, Ana; CARNEIRO, Davide; NOVAIS, Paulo; ANDRADE, Francisco. Sistema de resolução on-line de conflito para partilhas de bens: divórcios e heranças. II Simpósio de Informática, 9-10 set. 2010.

CARNEIRO, Davide; GOMES, Marco; COSTA, Ângelo; NOVAIS, Paulo; NEVES, José. Enriching conflict resolution environments with the provision of context information. Expert Systems, v. 34, n. 5, out. 2017.

CARNEIRO, Davide; NOVAIS, Paulo; ANDRADE, Francisco; ZELEZNIKOW, John; NEVES, José. Using case-based reasoning and principled negotiation to provide decision support for dispute resolution. Knowledge Information Systems, v. 36, p. 789-826, 2013.

CELLA, José Renato Gaziero. Controle das decisões jurídicas pela técnica do autoprecedente: lógica deôntica paraconsistente aplicada em sistemas especialistas legais. Tese (Doutorado) - Programa de Pós-Graduação em Direito da Universidade Federal de Santa Catarina, Florianópolis, 2008.

CONSELHO NACIONAL DE JUSTIÇA (CNJ). Justiça em Números 2018 (ano-base 2017). Brasília: CNJ, 2018 a.

CONSELHO NACIONAL DE JUSTIÇA (CNJ). Metas Nacionais do Poder Judiciário para 2019. Brasília: CNJ, 2018b.

CREVIER, Daniel. AI: the tumultuous history of the search for artificial intelligence. New York: Basic Books, 1993.

DA COSTA, Newton; KRAUSE, Décio; BUENO, Otávio. Paraconsistent logics and paraconsistency. In: JACQUETTE, Dale (ed.). Handbook of Philosophy of Science. Philosophy of Logic. North Holland: Elsevier, 2007. p. 791-911. 
DREYFUS, Hubert. What Computers Still Can't Do: A Critique of Artificial Reason. Cambridge: The MIT Press, 1999.

EBNER, Noam; ZELEZNIKOW, John. Fairness, Trust and Security in Online Dispute Resolution. Hamline University's School of Law's Journal of Public Law and Policy, v. 36, n. 2, Article 6, 2015.

ETZIONI, Amitai; EZTIONI, Oren. Should artificial intelligence be regulated? Issues in Science and Technology. 2017. Disponível em: https://papers.ssrn.com/sol3/papers.cfm?abstract_id=2993506. Acesso em: 8 dez. 2018.

FERRAZ JR., Tercio Sampaio. Função social da dogmática jurídica. 2. ed. São Paulo: Atlas, 2015.

FUJITA, Maíra de Oliveira Lima Ruiz; ALMEIDA, Bianca Santos Cavalli. Meios de solução digital de conflitos - Online Dispute Resolution (ODR). Revista de Processo, Jurisdição e Efetividade da Justiça, v. 5, n. 2, p. 19-35, 2019.

GLOBAL DIGITAL REPORT. Essential insights into internet, social media, mobile, and ecommerce use around the world. 2018. Disponível em: https://wearesocial.com/blog/2018/01/global-digital-report-2018. Acesso em: 12 fev. 2021.

HM COURTS \& TRIBUNALS SERVICE. Money Claim Online - User Guide for Claimants. 2017. Disponível em: https: / / assets.publishing.service.gov.uk/government/uploads/system/uploads/attachment_data/ file/762843/mcol-userguide-eng.pdf. Acesso em: 9 jul. 2019.

INSTITUTO BRASILEIRO DE PESQUISA DE GEOGRAFIA E ESTATÍSTICA (IBGE). Pesquisa Nacional por Amostra da Dados Contínua. 2016. Disponível em: https: / /agenciadenoticias.ibge.gov.br/ media/com_mediaibge/arquivos/c62c9d551093e4b8e9d9810a6d3bafff.pdf. Acesso em: 11 jul. 2019.

INTERNET CORPORATION FOR ASSIGNED NAMES AND NUMBERS (ICANN). Online Dispute Resolution Standards of Practice. 2009. Disponível em: https://www.icann.org/en/system/files/files / odr-standards-of-practice-en.pdf. Acesso em: 9 jul. 2019.

KATSH, Ethan; RIFKIN, Janet. Online Dispute Resolution: resolving conflicts in cyberspace. San Francisco: Jossey-Bass, 2001.

KATSH, Ethan; RIFKIN, Janet; GAITENBY, Alan. E-Commerce, E-Disputes, and E-Dispute Resolution: in the Shadow of "eBay Law". Ohio State Journal on Dispute Resolution, v. 15, n. 3, p. 705-734, 2000.

LATOUR, Bruno; WOOLGAR, Steve. Laboratory Life: The Construction of Scientific Facts. 2. ed. New Jersey: Princeton University Press, 1986. 
LIMA, Gabriela Vasconcelos; FEITOSA, Gustavo Raposo Pereira. Online dispute resolution (ODR): a solução de conflitos e as novas tecnologias. Revista do Direito, v. 3, n. 50, p. 53-70, 2016.

LODDER, Arno; ZELEZNIKOW, John. Developing an Online Dispute Resolution Environment: dialogue tools and negotiation support systems in a three-step model. Harvard Negotiation Law Review, v. 10, p. 287-337, 2005.

MCCARTHY, John. What is Artificial Inteligence? Computer Science Department, Stanford University, 2007. Disponível em: http://www-formal.stanford.edu/jmc/whatisai/whatisai.html. Acesso em: 11 jul. 2019.

REINO UNIDO. Traffic Penalty Tribunal. 2014. Disponível em: https://www.trafficpenaltytribunal. gov.uk/. Acesso em: 9 jul. 2019.

ROVER, Aires José. Representação do conhecimento legal em sistemas especialistas: o uso da técnica de enquadramentos. Tese (Doutorado) - Programa de Pós-Graduação em Direito da Universidade Federal de Santa Catarina, Florianópolis, 1999.

SELA, Ayelet. Can computers be fair? How automated and human-powered online dispute resolution affect procedural justice in mediation and arbitration. Ohio State Journal on Dispute Resolution, v. 33, n. 1, p. $91-148,2018$.

SERBENA, Cesar Antonio. Lógica e Direito: elementos para uma reconstrução formal do raciocínio jurídico. Tese (Doutorado) - Programa de Pós-Graduação em Direito da Universidade Federal do Paraná, Curitiba, 2003.

SOUZA NETTO, José Laurindo de; FOGAÇA, Anderson Ricardo; GARCEL, Adriane. Métodos autocompositivos e as novas tecnologias em tempos de COVID-19: online dispute resolution - ODR. Relações Internacionais no Mundo Atual, v. 1, n. 26, p. 21-32, 2020.

THOMAS, Kenneth; KILMANN, Ralph. Thomas-Kilmann Conflict Mode Instrument. CPP. 2008. Disponível em: http://www.organizationimpact.com/wp-content/uploads/2016/08/TKI_Sample_ Report.pdf. Acesso em: 9 jul. 2019.

UNIÃO EUROPEIA (UE). Regulamento n. 524, de 21 de maio de 2013, sobre a resolução de litígios de consumo em linha. Disponível em: https: / / eur-lex.europa.eu/legal-content/PT/TXT/?uri=CELEX:32013R0524. Acesso em: 12 fev. 2021.

UNITED NATIONS COMMISSION ON INTERNATIONAL TRADE LAW (UNCITRAL). Uncitral Technical Notes on Online Dispute Resolution. 2017. Disponível em: https://uncitral.un.org/sites/uncitral. 
un.org/files/media-documents/uncitral/en/v1700382_english_technical_notes_on_odr.pdf. Acesso em: 4 mar. 2021.

VIÑALS, Immaculada Barral. Consumidores, online dispute resolution y reclamaciones de pequeña cuantía. Democracia Digital e Governo Eletrônico, Florianópolis, n. 10, p. 394-415, 2014.

VINUTO, Juliana. A amostragem em bola de neve na pesquisa qualitativa: um debate em aberto. Temáticas, Campinas, v. 22, n. 44, p. 203-220, ago./dez. 2014.

WANG, Faye Fangfei. Online Dispute Resolution: technology, management and legal practice from an international perspective. Oxford: Chandos, 2009.

ZANFERDINI, Flávia Almeida Montingelli; OLIVEIRA, Rafael Tomaz. Online dispute resolution in Brazil: are we ready for this cultural turn? Revista Paradigma, v. 24, n. 1, p. 68-80, 2015.

ZELEZNIKOW, John. Building decision support systems in discretionary legal domains. International Review of Law Computers \&Technology, v. 14, n. 3, p. 341-356, 2000.

\section{COMO CITAR ESTE ARTIGO:}

MOULIN, Carolina Stange Azevedo. Métodos de resolução digital de controvérsias: estado da arte de suas aplicações e desafios. Revista Direito GV, v. 17, n. 1, jan./abr. 2021, e2108. https://doi.org/10.1590/23176172202108
Carolina Stange Azevedo Moulin Doutoranda em Filosofia e Teoria Geral do Direito na Faculdade de Direito da Universidade de São Paulo (USP). Graduada em DiREITO PELA Universidade FEderal do ESPÍRITO SANTO. cmoulinausp.br 